\title{
In vitro efficacy of Artemisia extracts against SARS-CoV-2
}

Chuanxiong Nie ${ }^{1,2}$, Jakob Trimpert ${ }^{1}$, Sooyeon Moon ${ }^{3}$, Rainer Haag ${ }^{2}$, Kerry Gilmore ${ }^{3,4}$, Benedikt B. Kaufer ${ }^{\text {* }^{*}}$ and Peter H. Seeberger ${ }^{2,3^{*}}$ (D)

\begin{abstract}
Background: Traditional medicines based on herbal extracts have been proposed as affordable treatments for patients suffering from coronavirus disease 2019 (COVID-19) caused by severe acute respiratory syndrome coronavirus 2 (SARS-CoV-2). Teas and drinks containing extracts of Artemisia annua and Artemisia afra have been widely used in Africa in efforts to prevent SARS-CoV-2 infection and fight COVID-19.

Methods: The plant extracts and Covid-Organics drink produced in Madagascar were tested for plaque reduction using both feline coronavirus and SARS-CoV-2 in vitro. Their cytotoxicities were also investigated.

Results: Several extracts as well as Covid-Organics inhibited SARS-CoV-2 and FCoV infection at concentrations that did not affect cell viability.

Conclusions: Some plant extracts show inhibitory activity against FCoV and SARS-CoV-2. However, it remains unclear whether peak plasma concentrations in humans can reach levels needed to inhibit viral infection following consumption of teas or Covid-Organics. Clinical studies are required to evaluate the utility of these drinks for COVID-19 prevention or treatment of patients.
\end{abstract}

Keywords: Artemisia annua, Artemisia afra, Antivirals, COVID-19, Covid-organics, Feline coronavirus (FCoV), SARSCoV-2

\section{Background}

Severe acute respiratory syndrome coronavirus 2 (SARS$\mathrm{CoV}-2)[1]$ has caused a pandemic of coronavirus disease 2019 (COVID-19) [2-4] that resulted in a rising death toll as well as serious economic and societal consequences. Several vaccines were developed and approved in record speed, and are now being distributed as quickly as possible [5, 6]. Still, affordable anti-viral treatments will still be needed for those that are not vaccinated or where vaccines fail to work. The clinical benefits of Remdesivir, the

\footnotetext{
*Correspondence: Benedikt.Kaufer@fu-berlin.de

${ }^{1}$ Institute for Virology, Freie Universität Berlin, Robert von Ostertag-Str. 7-13, 14163 Berlin, Germany

${ }^{2}$ Department of Chemistry and Biochemistry, Freie Universität Berlin, Takustrasse 3, 14195 Berlin, Germany

Full list of author information is available at the end of the article
}

only antiviral drug approved for treatment of COVID-19, are being discussed controversially [7], such that COVID19 treatment remains largely supportive. Repurposing of drugs already licensed for other diseases is a comparatively fast method to meet the urgent need for effective antivirals against SARS-CoV-2. Artesunate 2 and other synthetic derivatives of the sesquiterpene lactone natural product artemisinin 1 (Fig. 1) that is isolated from Artemisia annua plants, are the key active pharmaceutical ingredient (API) of WHO-recommended anti-malaria combination therapies, used in millions of patients every year with few side effects [8]. Teas made from the leaves of A. аnпиа plants are recommended in Traditional Chinese Medicine to treat malaria [9] and teas from Artemisia plants are widely used in many African countries to treat malaria patients, albeit contrary to WHO recommendations [10]. original author(s) and the source, provide a link to the Creative Commons licence, and indicate if changes were made. The images or other third party material in this article are included in the article's Creative Commons licence, unless indicated otherwise in a credit line to the material. If material is not included in the article's Creative Commons licence and your intended use is not permitted by statutory regulation or exceeds the permitted use, you will need to obtain permission directly from the copyright holder. To view a copy of this licence, visit http://creativecommons.org/licenses/by/4.0/. The Creative Commons Public Domain Dedication waiver (http://creativeco mmons.org/publicdomain/zero/1.0/) applies to the data made available in this article, unless otherwise stated in a credit line to the data. 


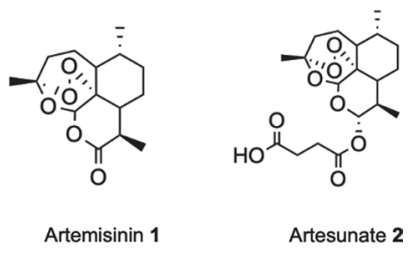

Fig. 1 Chemical structures of artemisinin 1, derived by isolation from $A$. annua plants and the semi-synthetic derivative artesunate $\mathbf{2}$ that is the active pharmaceutical ingredient in WHO-recommended anti-malarial medications

Artemisinin and its synthetic derivatives have shown impressive effects against other parasitic infections [11], a range of different types of cancer [12] and viruses [13] in vitro and in human clinical trials. In addition to pure, semi-synthetic substances, Artemisia teas and plant material have been explored for use to treat different diseases [14]. A. annua extract had shown anti-viral activity in vitro against SARS-CoV in 2005 [15] and SARS-CoV-2 (EC $\mathrm{E}_{50}$ value: $2.5 \mu \mathrm{g} / \mathrm{mL}$ ) $[16,17]$. Standardized $A$. annua extracts with high artemisinin content are currently being studied in an ongoing phase 2 clinical trial against COVID-19 [18]. Artesunate 2 was significantly more active than $A$. annua extracts against SARS-CoV-2 in vitro [16]. The excellent safety profiles of artemisininbased drugs in humans and their ready availability for worldwide distribution at a relatively low cost render them attractive repurposing candidates for treatment of COVID-19.

Early during the pandemic, traditional medicines made from plant extracts were employed in various countries in efforts to prevent COVID-19 infections or treat COVID-19 patients. In South Africa, teas of $A$. afra that-in contrast to A. annua-do not contain artemisinin 1, were used widely without in vitro or clinical data [19]. In Madagascar, Covid-Organics, a drink containing mainly $A$. annua extract and/or plant material, was announced by the President of Madagascar Andry Rajoelina as a "miracle cure" in April 2020, subsequently used in the country and exported to several African nations in hope to prevent and treat COVID-19 infections [20]. Due to fears that artemisinin combination therapies against malaria may become ineffective if artemisinin-based treatments are used against COVID19 , the WHO issued a warning against the use of traditional medicines [21]. More recently, the WHO modified its recommendation and called for an investigation into the potential efficacy of plant-based treatments [22]. To date, no in vitro data concerning anti-viral effects of $A$. afra plant extracts or Covid-Organics has been disclosed. Here, we report that various $A$. annua as well as $A$. afra plant extracts and Covid-Organics exhibit some antiviral activity against SARS-CoV-2 in vitro. It is unclear whether the plasma concentrations that can be achieved in humans using such extracts are sufficient to prevent or treat COVID-19 infections. Human clinical trials will be required to answer the question whether the traditional medicines may indeed have an effect in preventing or treating COVID-19 infections.

\section{Methods}

Plant material

Dried leaves of Artemisia plants grown in different countries and in different years were obtained as donations (see Addoitional file 1). Covid-Organics was purchased in Madagascar.

\section{Extraction}

Distilled water $(10 \mathrm{~mL})$ was heated to $90{ }^{\circ} \mathrm{C}$ in an Erlenmeyer flask. Dried plant material $(1 \mathrm{~g})$ was added to the solvent and kept for two minutes at $90{ }^{\circ} \mathrm{C}$, then $20 \mathrm{~min}$ at room temperature. The mixture was filtered using filter paper and solid material washed with fresh distilled water $(20 \times 2 \mathrm{~mL})$. The solvent was removed by rotary evaporation and the solid material was stored at $-10{ }^{\circ} \mathrm{C}$ prior to sample preparation. An ethanolic extract of $A$. annua var. $C P Q B A 1$ was prepared by treating $50 \mathrm{~g}$ of dried leaves of $A$. annua with $250 \mathrm{~mL}$ of ethanol at $50{ }^{\circ} \mathrm{C}$ for $200 \mathrm{~min}$.

\section{Sample preparation}

Aqueous Extract: Dried extract $(\sim 135 \mathrm{mg})$ was warmed to room temperature before dimethylsulfoxide (DMSO, $3 \mathrm{~mL}$ ) was added and the mixture heated $\left(40{ }^{\circ} \mathrm{C}\right)$ to ensure solvation. The solution was filtered using a syringe filter and stored in a snap-close vial at $-20{ }^{\circ} \mathrm{C}$ prior to use. Final concentration: $\sim 45 \mathrm{mg} / \mathrm{mL}$.

\section{Ethanolic extract}

Dried extract $(61 \mathrm{mg})$ was warmed to room temperature before dimethylsulfoxide (DMSO, $3 \mathrm{~mL}$ ) was added and the mixture heated $\left(40{ }^{\circ} \mathrm{C}\right)$ to ensure solvation. The solution was filtered using a syringe filter and stored in a snap-close vial at $-20{ }^{\circ} \mathrm{C}$ prior to use. Final concentration: $\sim 20 \mathrm{mg} / \mathrm{mL}$.

\section{Cell culture}

African green monkey kidney VeroE6 cells (ATCC CRL-1586) and Crandell-Rees Feline Kidney (CRFK, ATCC CCL-94) cells were maintained at $37{ }^{\circ} \mathrm{C}$ with $5 \%$ $\mathrm{CO}_{2}$ in Minimum Essential Medium (MEM; PAN Biotech, Aidenbach, Germany) supplemented with $10 \%$ fetal bovine serum (PAN Biotech), $100 \mathrm{IU} / \mathrm{mL}$ penicillin $\mathrm{G}$ and $100 \mu \mathrm{g} / \mathrm{mL}$ streptomycin (Carl Roth, Karlsruhe, Germany). 


\section{Virus isolates}

The SARS-CoV-2 BavPat 1 isolate (SARS-CoV-2/human/ Germany/BavPat 1/2020) was provided by Dr. Daniela Niemeyer and Dr. Christian Drosten (Charité, Berlin, Germany) and obtained from an outbreak in Munich, Germany, in February 2020 (BetaCoV/Germany/BavPat1/2020). Feline coronavirus (ATCC VR-989, WSU 79-1683) was propagated and titrated on CRFK cells [23].

\section{Plaque reduction antiviral assay}

Tenfold dilutions of the compounds described above were prepared in cell culture medium. To determine the effect of the compounds, dilutions were incubated with 100 plaque forming units (PFU) of FCoV or SARS-CoV-2 for one hour at $37{ }^{\circ} \mathrm{C}$. The compound-virus mix was incubated with CRFK or VeroE6 cells for $45 \mathrm{~min}$ at room temperature respectively. The cells were washed with PBS once, overlayed with $1.3 \%$ sample-free methylcellulose containing medium and plaque formation was assessed two days post infection. Plaques of FCoV were stained with specific antibodies (primary antibody: mouse antifeline coronavirus nucleocapsid protein monoclonal antibody at $1 \mu \mathrm{g} / \mathrm{mL}$, Bio-Rad; secondary antibody: Alexa 488-labeled goat anti-mouse IgG at a $1 \mu \mathrm{g} / \mathrm{mL}$; ThermoFisher) and counted manually by fluorescence microscopy (Axio observer, Zeiss). SARS-CoV-2 plaques were stained using crystal violet.

\section{Cell viability assays in CRFK and VeroE6 cells}

To evaluate cytotoxic effects of the tested extracts, compounds and diluent (DMSO), cell viability was studied using Cell Counting Kit-8 (CCK8, Merck, Germany). The protocol was the same for CRFK and VeroE6 cells: cells were seeded at 10,000 cells per well of flat bottom 96-well plates (Thermo Fisher Scientific, Roskilde, Denmark). The next day, medium was exchanged containing specified concentrations of the samples. Each concentration or dilution was tested in three replicates; at least six nontreated control wells were included in the assay. After $45 \mathrm{~min}$ or $24 \mathrm{~h}$ of incubation at $37^{\circ} \mathrm{C}$ and $5 \% \mathrm{CO}_{2}, \mathrm{CCK} 8$ Reagent $(10 \mu \mathrm{L})$ was added per well and plates were incubated for $1 \mathrm{~h}$ at $37^{\circ} \mathrm{C}$, prior to recording absorbance at $450 \mathrm{~nm}$ using a FLUOstar OPTIMA 96-well plate reader (BMG LABTECH, Offenburg, Germany). The viability of CRFK cells was only tested after 45 min incubation. Absorbance recorded in each well was related to the average absorbance of nontreated control wells to calculate the percentage of cell viability. $1 \%$ SDS was used as negative control. Sigmoidal dose response curves were fitted, and median cytotoxic concentration $\left(\mathrm{CC}_{50}\right)$ values were calculated with GraphPad Prism 8.0.0.

\section{Results}

Extracts and compounds

$A$. annua and $A$. afra plants ( $1 \mathrm{~g}$ ) were extracted using distilled water $(10 \mathrm{~mL})$ at $90{ }^{\circ} \mathrm{C}$ for two minutes and then $20 \mathrm{~min}$ at room temperature. Solids were removed by filtration and the solvent evaporated. The extracted materials $(\sim 135 \mathrm{mg})$ were dissolved in DMSO $(3 \mathrm{~mL})$ and filtered, each to a concentration of $\sim 45 \mathrm{mg} / \mathrm{mL}$. Artemisinin (500 mg) was dissolved in DMSO (3 mL). Covid-Organics $(50 \mathrm{~mL})$ was dried by rotary evaporation and dissolved in DMSO (3 mL) (see Additional file 1 for details).

\section{Inhibition of feline coronavirus (FCoV) plaque formation by plant extracts and Covid-Organics}

To assess the antiviral activity of the extracts and pure artemisinin, we first used the feline coronavirus (FCoV), a biological safety level (BSL) 2 coronavirus related to SARS-CoV-2 that can be handled outside of a BSL3 facility. The extracts were diluted tenfold in DMEM medium and pre-incubated with 100 PFU of FCoV virus for $45 \mathrm{~min}$ at room temperature. Virus and inhibitor mix were incubated with a monolayer of CRFK cells and plaque formation was assessed two days post infection. A typical dose-dependent curve of virus inhibition is shown in Fig. 2. All samples inhibited the virus at high concentrations. The antiviral activity was clearly reduced below $1 \mathrm{mg} / \mathrm{mL}$, as no virus inhibition was observed, while all samples showed similar activity at the range of $0.5-1 \mathrm{mg} / \mathrm{mL}$. The half maximal effective concentration $\left(\mathrm{EC}_{50}\right)$ was estimated based on these curves (Additional file 1: Table S1). A. annua var. CPQBA 1 alcoholic extract inhibitited $\mathrm{FCoV}$ with an $\mathrm{EC}_{50}$ of $0.002 \pm 0.001 \mathrm{mg} / \mathrm{mL}$. The toxicities were also evaluated by CCK- 8 (data are shown in Additional file 1: Figure S1 and Table S1).

Covid-Organics showed moderate inhibitory activity against FCoV (Additional file 1: Figure S2). The most promising samples based on the FCoV inhibition data

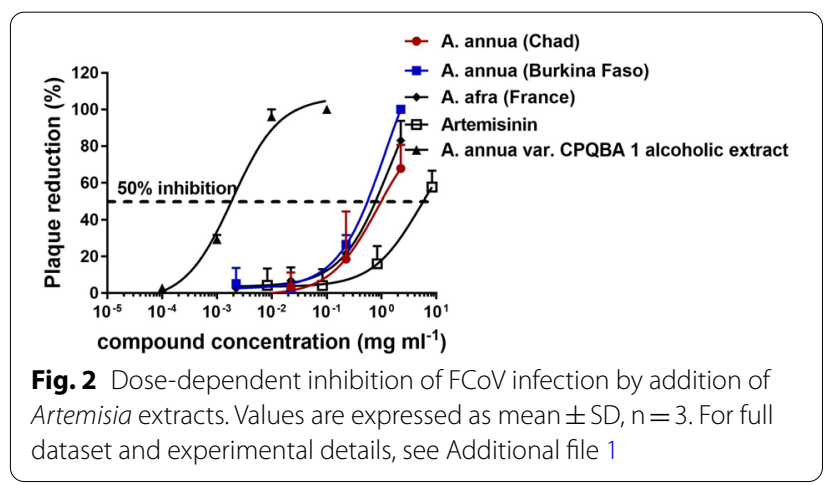


Table 1 Selected dried leaves, extracts and Covid-Organics drink tested for activity. Year corresponds to when the plant material was harvested or extract/commercial drink was produced. For a full list of samples tested, please see Additiona file 1

\begin{tabular}{lll}
\hline Type & Region & Year \\
\hline A. annua & USA & 2019 \\
A. annua & Chad & 2019 \\
A. annua & Burkina Faso & 2019 \\
A. annua var. CPQBA 1 alcoholic & Brazil & 2020 \\
extract & & \\
A. afra & France & 2015 \\
Covid-Organics & Madagascar & 2020 \\
Artemisinin 1 & - & - \\
\hline
\end{tabular}

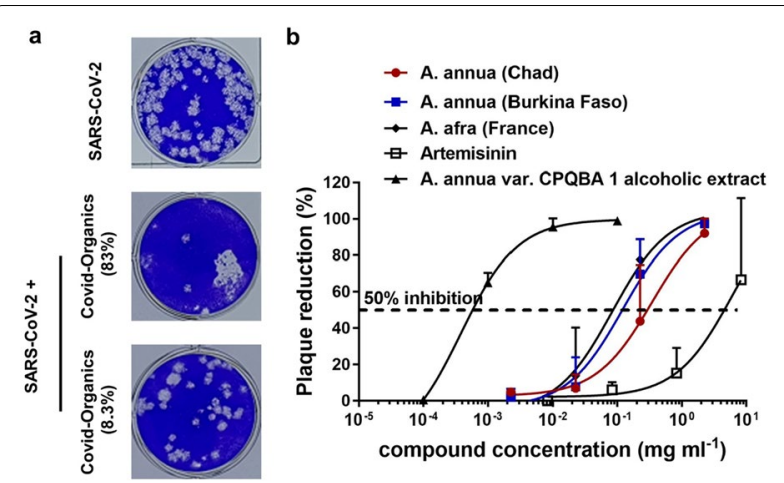

Fig. 3 (a) Images of the SARS-CoV-2 plaques incubated with different dilutions of Covid-Organics. The dose is expressed by percentage of the raw drink. (b) Concentration-dependent inhibition of SARS-CoV-2 infection using different extracts. Here, SARS-CoV-2 was preincubate with indicated compounds for $45 \mathrm{~min}$ and the mixture subsequently added to VeroE6 cells for another $45 \mathrm{~min}$. Then, the cells were washed with PBS to remove unboundvirions and covered with Avicel overlay medium for three days until plaque formation. Please note that the testing protocol is different from Ref. 16. Values are expressed as mean $\pm S D, n=3$

were selected for in vitro inhibition studies using SARSCoV-2 in the BSL3 facility (Table 1).

\section{In vitro Inhibition of SARS-CoV-2 plaque formation by Artemisia extracts and Covid-Organics}

The extracts with the highest activity in on $\mathrm{FCoV}$ were subsequently tested for their antiviral activity against SARS-CoV-2 using plaque reduction assays. SARS$\mathrm{CoV}-2$ plaque numbers were reduced following incubation with the extracts at $0.225 \mathrm{mg} / \mathrm{mL}$, while no activity was detected at $0.0225 \mathrm{mg} / \mathrm{mL}$. A. annua and $A$. afra aqueous extract as well as an $A$. annua ethanolic extract showed the inhibition with $\mathrm{EC}_{50}$ values below $0.1 \mathrm{mg} / \mathrm{mL}$ (Fig. 3, Table 2). Similar to the results of FCoV inhibition,
Table 2 Inhibitory activity of the extracts against two different types of coronaviruses. The results for FCoV inhibition, including EC50 and CC50 values, are shown in Additional file 1: Table S1

\begin{tabular}{llcc}
\hline Sample & $\begin{array}{l}\mathrm{EC}_{50} \text { SARS-CoV-2 } \\
(\mathbf{m g} / \mathbf{m L})\end{array}$ & $\begin{array}{l}\mathrm{CC}_{50} \text { VeroE6 } \\
(\mathbf{m g} / \mathbf{m L})\end{array}$ & $\begin{array}{l}\text { Selectivity } \\
\text { Index } \\
\text { (SARS- } \\
\text { CoV-2) }\end{array}$ \\
\hline A. annua (Chad) & $0.28 \pm 0.08$ & $1.96 \pm 0.82$ & 7.00 \\
A. annua (Burkina Faso) & $0.12 \pm 0.03$ & $2.66 \pm 1.48$ & 22.17 \\
A. afra (France) & $0.09 \pm 0.03$ & $2.36 \pm 1.08$ & 26.22 \\
A. annua var. (Brazil) & $0.13 \pm 0.04$ & $2.64 \pm 1.44$ & 20.31 \\
A. annua var. CPQBA 1 & $0.0004 \pm 0.0001$ & $0.11 \pm 0.04$ & 275.00 \\
alcoholic extract & & & \\
Artemisinin & $4.23 \pm 1.88$ & $18.18 \pm 8.6$ & 4.30 \\
A. annua (USA) & $0.46 \pm 0.09$ & $1.63 \pm 0.63$ & 3.54 \\
\hline
\end{tabular}

Table 3 Inhibitory activity of Covid-Organics against two different coronaviruses. The results for FCoV inhibition, including EC50 and CC50 values, are shown in Additional file 1: Table S1

\begin{tabular}{llll}
\hline Sample & $\begin{array}{l}\mathrm{EC}_{50} \text { SARS-CoV-2 } \\
\text { (\% to raw drink) }\end{array}$ & $\begin{array}{l}\mathrm{CC}_{50} \text { VeroE6 } \\
\text { (\% to raw drink) }\end{array}$ & $\begin{array}{l}\text { Selectivity } \\
\text { Index (SARS- } \\
\text { CoV-2) }\end{array}$ \\
\hline $\begin{array}{l}\text { Covid-Organics } \\
\text { (Madagascar) }\end{array}$ & $7.73 \pm 1.24$ & $40.85 \pm 12.94$ & 5.28 \\
\hline
\end{tabular}

A. annua var. CPQBA 1 alcoholic extract was the best inhibitor with an EC50 of $0.0004 \pm 0.0001 \mathrm{mg} / \mathrm{mL}$.

The cytotoxicity of all samples towards VeroE6 cells was assessed to ensure that any antiviral effects were not caused by toxicity. Using the Cell Counting Kit-8, the 50\% cytotoxic concentration $\left(\mathrm{CC}_{50}\right)$ of each extract in VeroE6 cells was determined and showed a similar toxicity profile with a $\mathrm{CC}_{50}$ around $10-20 \mathrm{mg} / \mathrm{mL}$ (Fig. 4, Table 2). The selectivity index (SI) was assessed by CC50/EC50. The aqueous extracts of $A$. annua from Burkina Faso and Brazil and $A$. afra from France showed an $\mathrm{SI}>20$. A. annua var. CPQBA 1 alcoholic extract showed an $\mathrm{SI}>200$. These tests confirmed that the extracts can inhibit the infection of SARS-CoV-2 at levels that are not toxic to the cells.

The Covid-Organics drink was first concentrated by rotary evaporation and then diluted for the test. As the exact mass concentration was unknown, the inhibitory activity is shown as percentage to the raw drinks (Table 3). The $\mathrm{EC}_{50}$ against SARS-CoV-2 was determined to be $7.73 \%$ of raw drink using the plaque reduction assay. The selectivity index was thereby 5.28 .

\section{Discussion}

Natural products have been a rich source for the discovery of new drugs. For thousands of years humans have turned to plants in attempts to prevent, alleviate, or heal 


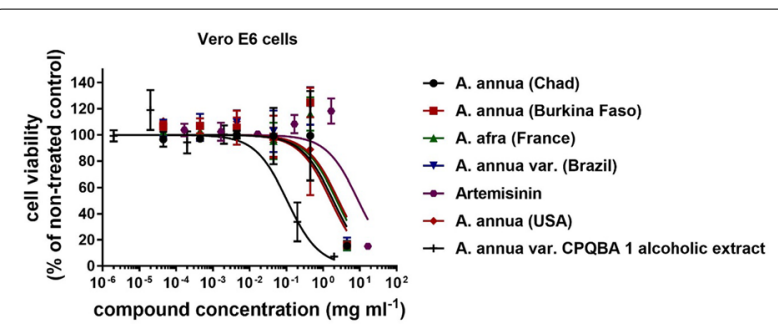

Fig. 4 Viability of VeroE6 cells being cultured in presence of the samples for $45 \mathrm{~min}$. Values are expressed as mean $\pm S D, n=3$

different diseases. Today, these "traditional medicines" have been broadly replaced by synthetic active pharmaceutical ingredients. Still, compounds obtained by isolation from plants are used in modern approaches to treat infectious diseases, cancer, and other ailments. Many natural products exhibit antiviral activities [24]. Artemisinin, isolated from $A$. annua plants, and the semi-synthetic derivative artesunate 2 obtained by chemical modification, inhibit a variety of viruses[13] including SARS$\mathrm{CoV}$ [15]. Given the similarities between SARS-CoV and SARS-CoV-2, we investigated the use of artemisinin $\mathbf{1}$ (Fig. 1), artemisinin derivatives such as artesunate 2 , as well as $A$. апnua extracts for the inhibition of SARSCoV-2 in vitro [16]. Artesunate was found to be most effective in inhibiting the virus, but $A$. annua extracts also revealed some activity in vitro. Human phase 2 clinical trials are currently ongoing to test the efficacy of these substances in treating COVID-19 [18]. Other groups reported similar findings concerning pure synthetic artemisinin derivatives [25] and whole $A$. annua plant material [17].

Reports that teas made from $A$. annua and $A$. afra plants [19], as well as Covid-Organics, a drink made from A. annua leaves and Ravensara aromatica in Madagascar [20], have been used throughout Africa. Our earlier observation that $A$. аnnua extracts can inhibit SARSCoV-2 in vitro prompted us to test whether such extracts can indeed inhibit coronaviruses. To assess the inhibitory activity of the different plant extracts against two different coronaviruses, the feline $\mathrm{CoV}$ and a human isolate of SARS-CoV-2, we performed plaque reduction assays in vitro. Screening of samples was performed using FCoV in a biosafety level (BSL)-2 facility in blind fashion. The activity of the most promising samples was subsequently tested in a BSL3 facility using a SARS-CoV-2 isolate. Short pre-incubation with the extracts significantly inhibited plaque formation of both viruses, indicating that the extracts suppress viral infection in a dose dependent manner in vitro (Fig. 3).

Some differences in the inhibitory activity against FCoV and SARS-CoV-2 were observed and confirm reports that SARS-CoV-2 is more sensitive to antivirals than FCoV [26]. The extracts, with some slightly varying activities, were found to inhibit both coronavirus FCoV and SARS-CoV-2. Among the active samples were extracts of $A$. аnnua and $A$. afra plants, especially the alcoholic extract of $A$. annua var. CPQBA 1 (Fig. 3). This finding was surprising considering that $A$. afra does not contain artemisinin and even more so since synthetic artesunate, a pharmacokinetically improved derivative of artemisinin, proved most active in previous in vitro SARS-CoV-2 inhibition studies [16, 25]. Our findings suggest that not just artemisinin, but also other compounds present in the Artemisia extracts have inhibitory effects towards SARS-CoV-2. It has been suggested that flavonoids present in Artemisia species are active against SARS-CoV-2 [27]. It should be noted that the EC50 value of artemisinin differs from a previous report [16] due to differences in the treatment duration. The previous study measured a reduction in viral replication and spread in the presence of the drug over $24 \mathrm{~h}$ of infection. In contrast, we assessed whether a short prophylactic treatment (45 min) can prevent infection with SARS-CoV-2 in this study. Therefore, results of these two studies are not directly comparable.

The commercial Covid-Organics drink prepared from A. annua plants was promoted by the president of Madagascar in April 2020 at the beginning of the COVID-19 pandemic without any published scientific support as to its efficacy. Subsequently, a controversy around the product and its use in several countries in Africa arose due to fears that the use of artemisinin containing extracts may result in a resistance to this drug by Plasmodium falciparum, the parasite that causes malaria. We felt it was important to test the extracts in vitro and determine whether this product has any antiviral activity. In our in vitro test, Covid-Organics was found to inhibit SARSCoV-2 at the concentrations we investigated (Fig. 3), with an $\mathrm{EC}_{50}$ of $7.73 \%$ to raw drink and a selectivity index of 5.28. Covid-Organics exhibited a higher antiviral activity against SARS-CoV-2 compared to FCoV, which could be attributed the different interactions with the viruses and/ or host cells. Even though inhibition of virus infection is noticed, the selectivity index is not very promising.

For all samples- $A$. annua and $A$. afra extracts as well as Covid-Organics-tested, it remains to be proven whether serum levels required to inhibit the virus can be reached in patients. Extracts showed some toxicity at higher concentrations but the selectivity index of 10 opens a useful therapeutic window to be explored in human clinical trials. It will have to be tested whether such extracts exhibit activity in the upper respiratory tract.

Artemisia extracts used as teas and Covid-Organics may be potential countermeasures for COVID-19. 
However, the in vitro inhibition data reported here needs to be followed up with investigations in animal models as well as human clinical trials before recommendations for use in patients can be made.

\section{Conclusions}

Different $A$. annua and $A$. afra extracts and the CovidOrganics drink produced in Madagascar inhibit SARS$\mathrm{CoV}-2$ and feline coronavirus (FCoV) infection in vitro at concentrations that did not affect cell viability. Clinical studies are required to evaluate the utility of these drinks for COVID-19 prevention or treatment in patients.

\author{
Abbreviations \\ API: Active pharmaceutical ingredient; BSL: Bio safety level; $\mathrm{CC}_{50}$ : $50 \%$ Cyto- \\ toxic concentration; COVID-19: Coronavirus disease 2019; CRFK: Crandell-Rees \\ Feline Kidney; DMSO: Dimethylsufoxide; $\mathrm{EC}_{50}$ : Half maximal effective con- \\ centration; FCoV: Feline coronavirus; MEM: Minimum Essential Medium; PBS: \\ Phosphate buffered saline; PFU: Plaque forming units; SARS-CoV-2: Severe \\ acute respiratory syndrome coronavirus 2; Sl: Selectivity index; WHO: World \\ Health Organization.
}

\section{Supplementary Information}

The online version contains supplementary material available at https://doi. org/10.1186/s12985-021-01651-8.

Additional file 1. The following are available: Figure S1: Viability of CRFK cells being cultured in presence of the samples for $45 \mathrm{~min}$. Values are expressed as mean $\pm S D, n=3$. Figure $\mathbf{S 2}$ : Inhibitory activity of CovidOrganics against two different coronaviruses. Values are expressed as mean $\pm S D, n=3$. Figure S3. Viability of VeroE6 cells being cultured in presence of the samples for $24 \mathrm{~h}$. Values are expressed as mean $\pm \mathrm{SD}, \mathrm{n}=3$. Table S1: List of dried leaves and compounds from various places and their inhibitory activity against FCoV.

\section{Acknowledgements}

We thank Lucile Cornet-Vernet for A. annua and A. afra plant material, Prof. Pedro Melillo de Magalhaes (Univ. de Campinas, Brazil) for A. annua plant material and A. annua ethanolic extract, Dr. H.M. Hirt for A. annua plant material and ArtemiLife Inc. for providing the A. annua plant material. We thank an anonymous donor for providing an unopened bottle of Covid-Organics obtained in Madagascar. We thank Ann Reum for technical assistance.

\section{Studies involving animals}

Not applicable.

\section{Authors' contributions}

Conceptualization, P.H.S., K.G. and B.B.K.; methodology, C.N. and J.T.; formal analysis, C.N. and J.T.; investigation, C.N. and J.T.; extraction, S.M.; sample preparation, S.M.; resources, P.H.S. and B.B.K.; writing-original draft preparation, review and editing, C.N., P.H.S. and B.B.K. with the input from all authors. All authors have read and agreed to the published version of the manuscript. All authors read and approved the final manuscript.

\section{Funding}

Open Access funding enabled and organized by Projekt DEAL. This research was funded by the Max Planck Society.

\section{Availability of data and materials}

The data supporting the findings is found in the supporting information any further requests for data should be addressed to the corresponding authors.

\section{Declarations}

Ethics approval and consent to participate

Not applicable.

\section{Consent to publication}

Not applicable.

\section{Competing interests}

K.G. is the director of ArtemiLife, Inc. K.G. and P.H.S. have a significant financial stake in ArtemiFlow GmbH, that is a shareholder in ArtemiLife, Inc. the company that provided one of the samples. All other authors have no competing interest.

\section{Author details}

${ }^{1}$ Institute for Virology, Freie Universität Berlin, Robert von Ostertag-Str. 7-13, 14163 Berlin, Germany. ${ }^{2}$ Department of Chemistry and Biochemistry, Freie Universität Berlin, Takustrasse 3, 14195 Berlin, Germany. ${ }^{3}$ Department for Biomolecular Systems, Max-Planck Institute for Colloids and Interfaces, Am Mühlenberg 1, 14476 Potsdam, Germany. ${ }^{4}$ Present Address: Department of Chemistry, University of Connecticut, 55 N. Eagleville Rd., Storrs, CT 06268, USA.

Received: 1 March 2021 Accepted: 29 August 2021

Published online: 08 September 2021

\section{References}

1. LT Phan TV Nguyen QC Luong TV Nguyen HT Nguyen HQ Le TT Nguyen TM Cao QD Pham 2020 Importation and human-to-human transmission of a novel coronavirus in vietnam New England Journal of Medicine 382 872874

2. C Huang Y Wang X Li L Ren J Zhao Y Hu L Zhang G Fan J Xu X Gu 2020 Clinical features of patients infected with 2019 novel coronavirus in wuhan, china The Lancet 395497506

3. CI Paules HD Marston AS Fauci 2020 Coronavirus infections-more than just the common cold JAMA 323707708

4. H Lu CW Stratton Y-W Tang 2020 Outbreak of pneumonia of unknown etiology in wuhan, china: The mystery and the miracle Journal of Medical Virology 92401402

5. F Krammer 2020 Sars-cov-2 vaccines in development Nature 586516527

6. W-H Chen U Strych PJ Hotez ME Bottazzi 2020 The sars-cov-2 vaccine pipeline: An overview Current Tropical Medicine Reports 76164

7. JH Beigel KM Tomashek LE Dodd AK Mehta BS Zingman AC Kalil E Hohmann HY Chu A Luetkemeyer S Kline 2020 Remdesivir for the treatment of covid-19 - final report N Engl J Med 38318131826

8. D Klayman 1985 Qinghaosu (artemisinin): An antimalarial drug from china Science 22810491055

9. Aftab, T.; Ferreira, J.F.S.; Khan, M.M.A.; Naeem, M. (Eds.) Artemisia annua Pharmacology and Biotechnology, Springer, 2014.

10. du Toit, A.; van der Kooy, F. Artemisia afra, a controversial herbal remedy or a treasure trove of new drugs? J Ethnopharmacol. 2019, 244, 112127.

11. I Adam OA Elhardello MO Elhadi E Abdalla KA Elmardi FH Jansen 2008 The antischistosomal efficacies of artesunate-sulfamethoxypyrazinepyrimethamine and artemether-lumefantrine administered as treatment for uncomplicated, Plasmodium falciparum malaria Ann Trop Med Parasitol. 1023944

12. T Efferth 2017 From ancient herb to modern drug: Artemisia annua and Artemisinin for cancer therapy Sem. Cancer Bio. 466583

13. T Efferth MR Romero DG WolfT Stamminger JJ Marin M Marschall 2008 The antiviral activities of artemisinin and artesunate Clin Infect Dis. 47804 11

14. Elfawal, M.A.; Towler, M.J.; Reich, N.G., Golenbock, D.; Weathers, P.J.; Rich, S.M.Dried whole plant Artemisia annua as an antimalarial therapy. PLoS One. 2012, 7, e52746. 
15. S-Y Li C Chen H-Q Zhang H-Y Guo H Wang L Wang X Zhang S-N Hu J Yu P-G Xiao R-S Li X Tan 2005 Identification of natural compounds with antiviral activities against SARS-associated coronavirus Antivir. Res. 6718 23

16. Y Zhou K Gilmore S Ramirez E Settels KA Gammeltoft LV Pham U Fahnøe S Feng A Offersgaard J Trimpert J Bukh K Osterrieder JM Gottwein PH Seeberger 2021 In vitro efficacy of Artemisinin-based treatments against SARS-CoV-2 Scientific Reports 1114571

17. Nair, M.S.; Huang, Y.; Fidock, D.A.; Polyak, S.J.; Wagoner, J.; Towler, M.J.; Weathers, P.J. Artemisia annua L. extracts prevent in vitro replication of SARS-CoV-2; J. Ethnopharmacol. 2021, 274, 114016

18. ClinicalTrials.gov Identifier: NCT04530617

19. Dandara, C.; Dzobo, K.; Chirikure, S. COVID-19 Pandemic and Africa: From the Situation in Zimbabwe to a Case for Precision Herbal Medicine. Omics A Journal of Integrative Biology 2020, 24, DOl: https://doi.org/10.1089/omi. 2020.0099

20. L Nordling 2020 Unproven herbal remedy against COVID-19 could fuel drug-resistant malaria, scientists warn Science https://doi.org/10.1126/ science.abc6665

21. Tih F. WHO holds meeting with African traditional medicine experts. 2020, [cited January 31, 2021]. Available from: https://www.aa.com.tr/en/africa/ who-holds-meeting-with-african-traditional-medicine-experts/1838004
22. World Health Organization, Regional Ofice for Africa. WHO supports scientifically-proven traditional medicine, May 4, 2020 [cited January 31, 2021]. https://www.afro.who.int/news/who-supports-scientificallyproven-traditional-medicine

23. SW Ng GT Selvarajah YK Cheah FM Kamal AR Omar 2020 Cellular Metabolic Profiling of CrFK Cells Infected with Feline Infectious Peritonitis Virus Using Phenotype Microarrays Pathogens 9412

24. LT Lin WC Hsu CC Lin 2014 Antiviral natural products and herbal medicines J Tradit Complement Med. 42435

25. R Cao H Hu Y Li Y Wang M Xu J Liu H Zhang Y Yan L Zhao W Li T Zhang D Xiao X Guo Y Li J Yang Z Hu M Wang W Zhong 2020 Anti-SARS-CoV-2 Potential of Artemisinins In Vitro ACS Infectious Diseases 625242531

26. S Paltrinieri A Giordano A Stranieri S Lauzi 2020 Feline infectious peritonitis (FIP) and coronavirus disease 19 (COVID-19): Are they similar? Transbound Emerg Dis. https://doi.org/10.1111/tbed.13856

27. Russo, M.; Moccia, S.; Spagnuolo, C.; Tedesco, I.; Russo, G.L.; Roles of flavonoids against coronavirus infection. Chem Biol Interact. 2020, 328, 109211.

\section{Publisher's Note}

Springer Nature remains neutral with regard to jurisdictional claims in published maps and institutional affiliations.
Ready to submit your research? Choose BMC and benefit from:

- fast, convenient online submission

- thorough peer review by experienced researchers in your field

- rapid publication on acceptance

- support for research data, including large and complex data types

- gold Open Access which fosters wider collaboration and increased citations

- maximum visibility for your research: over $100 \mathrm{M}$ website views per year

At BMC, research is always in progress.

Learn more biomedcentral.com/submissions 